\title{
Forecast and Analysis of China's Health Human Resources and Medical Higher Education Development Demand
}

Qin Liu

Yunnan University of Chinese Medicine https://orcid.org/0000-0002-1929-2686

Huai-mei BI

Yunnan University of Chinese Medicine

Li-xiong BI

Yunnan University of Chinese Medicine

Shuo-wei ZHANG

Yunnan University of Chinese Medicine

Ying-ping FU

Yunnan University of Chinese Medicine

Ren-jie CHANG ( $\nabla 303184827 @ q q . c o m$ )

https://orcid.org/0000-0002-9501-9171

Research article

Keywords: Health manpower, Education, ARIMA demand forecast

Posted Date: October 25th, 2019

DOl: https://doi.org/10.21203/rs.2.16525/v1

License: (1) This work is licensed under a Creative Commons Attribution 4.0 International License.

Read Full License 


\title{
Forecast and Analysis of China's Health Human Resources and Medical Higher Education Development Demand
}

\author{
LIU Qin ${ }^{1}$, BI Huai-mei ${ }^{1}$ BI Li-xiong ${ }^{1}$, CHANG Ren-jie ${ }^{2 *}$,
}

\section{Abstract}

Background: Statistics show that as of the end of December 2017, there were 11.749 million health workers and 898.82 million health technicians in China. In recent years, with the rapid development of the economy, the rapid expansion of the health manpower, which requires more scientific and rational health manpower forecasting, health manpower planning.It is important to strengthen and study the forecast of the future demand of the health workforce.

Methods: On the basis of analyzing the current situation, changing trend and problems of China's human resources allocation and higher medical education, this study uses ARIMA model to forecast the demand of health workers in China from 2018 to 2024, and compares the difference smaller supply and demand of China's total health manpower.To determine the future development trend of China's health manpower, and finally explore the scientific and reasonable forecasting method of human resources for health.

Results: China's total health manpower is relatively adequate, the proportion of medical care is unreasonable, medical staff is inadequate. The ARIMA model predicts an improvement in the inversion of health care in China and a continued increase in the demand for health care.By 2024, China's demand for health personnel will reach 17.4563 million, but the health manpower supply is still not keeping pace with the growth rate of demand, and the quantitative gap is still gradually widening in the short term, the gap between supply and demand in 2024 reached 1.4859 million people, medical and health institutions and medical education institutions are under greater pressure.

Conclusion: In view of the forecast results of China's health human resources in this study, policy makers and health managers should pay more attention to and support the forecastplanning of health human resources, strengthen the government's macro-control, and actively solve the shortage of health manpower. Actively explore scientific models or methods for forecasting the demand of health workers, guide the planning practice of health manpower, guide the training of health personnel in colleges and universities, moderately expand the scale of medical education and training, and vigorously improve the quality of medical education.

Keywords: Health manpower, Education, ARIMA demand forecast

The imbalance of health manpower is a common phenomenon in all countries of the world at present, mainly manifested in the uneven distribution of urban and rural areas, regions, unbalanced professional distribution, structural organization imbalance and so on[1]. The health manpower is the most important component of health resources and the decisive resource for the development of health[2-3]. The prediction of health manpower belongs to the allocation of human resources for health research, other countries in the world, such as the United Kingdom, have attached great importance to the allocation of health resources, through a series of efforts to regulate the cost of health resources, to promote citizens to access health services to the maximum equity of the [4-9]. Australia has also borrowed from the UK's health-care model[10-15]. Facing the new stage of the 13th Five-Year Plan, the State Council issued the 
Outline of the National Health Service System (2015-2020) in 2015. In October 2016, the State Council issued the Outline of the Healthy China 2030 Plan, one of the objectives of which is to promote the equalization of basic public services in the field of health, safeguard the public welfare of basic medical and health services, achieve universal health coverage and promote social equity. It also proposes to strengthen the training of health personnel and the incentive mechanism for evaluation of the use of innovative talents. On December 21, 2016, the Executive Meeting of the State Council deliberated and adopted the Health and Health Plan of the 13th Five-Year Plan and the Plan for Deepening the Reform of the Medical and Health System during the 13th Five-Year Plan. In short, in 2020 to achieve universal access to basic health services, health human resources construction and development will be the only way. Therefore, the use of model sturding and forecasting the future needs of the health workforce can effectively prevent the imbalance of the health manpower, not only to avoid the waste of resources caused by the surplus health manpower, but also to avoid the shortage of health manpower caused by the residents' medical and health services demand is difficult to meet ,has great significance[16-19].

\section{Methods}

Predictology as an important technical discipline, plays an increasingly important role in all walks of life today[20-21]. The 1990-2017 Health Human Resources Data are derived from the 2018 China Health Statistics Yearbook.More people/population ratio method, index smoothing method, gray prediction principle and method to predict the absolute demand of health manpower[22-29]. Kalman and Bucy began to study the uneven process of time series in the early 1960s, but did not form a certain system, prompting researchers to find ways to solve these problems[30-31]. The self-regression and moving average model prediction is shortly recorded as a model prediction method, which is an earlier and more accurate prediction method that can solve the nonlinear characteristics of the time series series. Model prediction mainly reveals the development law of event sequence from the angle of sequence self-correlation. In recent years, models have been widely used in energy, economy, electricity, construction, transportation, health and other fields for the scientific and reliable prediction of resources in various industries to provide the possibility[32-33].

Time series is the number of series formed by the number of the values of a statistical indicator in chronological order, there can be a deterministic relationship or a random relationship between the time and indicator series, the time series prediction method is to prepare and analyze the time series, according to the time series reflected in the development process, direction and trend, analogy or extension to predict the level that may be reached over the next period of time or some time thereafter. Previously, the researchers limited the time series to a smooth time series, but the time series data of many indicators did not have the characteristics of smooth, often with trend.

ARIMA model method is based on the model to predict the human health human resources in the target year, ARIMA ( $p, d, q)$ prediction model, AR is self-regression, $p$ is the self-regression order, MA is the moving average, $q$ is the moving average order, $d$ the number of differences made to make the time series a smooth sequence. The basic steps can be broadly divided into four steps: (1) the zero-mean processing and differential smoothing of the sequence, before modeling, the original base period data with a significant rise or downward trend should be 
processed to make it a set of stable sequences; The parameters are estimated, the statistically significant parameters are used for predictive analysis, and the $x 2$ test is used to self-corset the residual sequence of the model (also known as the residual white noise test) to determine whether the model fits completely, when $\mathrm{P}$ is all greater than 0.05 , the model fit is considered to fit better, the model diagnosis can pass.

\section{Results}

\subsection{The overall status of health workers in China}

By the end of 2017, the number of health workers in China had reached 11.749 million, of which: 898.82 million health technicians, accounting for 76.50 percent; Overall, the number of health technicians increased by 62.39 per cent. Among them: the number of practicing (assistant) physicians increased by 45.54 per cent and the number of registered nurses increased by 105.09 per cent.Total enrollment of medical students increased by $9 \%$ and the number of medical graduates increased by $37.52 \%$.

\subsection{Historical trends in China's health workforce}

The number of health technicians in China increased from 3.897million in 1990 to an average annual growth rate of $3.14 \%$ over 28 years, reaching an average annual growth rate of about 180,000, reaching 898.82 million in 2017. In 1990, China grew from an average of $2.45 \%$ and $5.17 \%$ to 3.39 million and 3.804 million in 2017, with the number of practicing (assistant) physicians and the number of registered nurses in 1990, with an average annual growth rate of $2.45 \%$ and $5.17 \%$. The number of medical students enrolled and graduated in China increased from 140,000 and 137,000 in 1990 to an average annual growth rate of $8.38 \%$ and $8.26 \%$ over 28 years, with an average annual growth rate of about 38,927 and 36,811 , reaching 1.23 million and 1.1678 million in 2017.

\subsection{Data smoothness processing}

By establish a data sequence diagram, sequence trend analysis of the sequence is required before ARIMA modeling. This study found that all the health human series data did not have obvious seasonal components, and through the analysis of self-correlation and partial correlation found that the sequence was non-stable, and the sequence overall showed a clear upward trend. Since the ARIMA model requires that the sequence is a smooth sequence, it is necessary to perform d-order differential operation to make it a smooth time sequence. The self-correlation and partial correlation graphs are drawn using SPSS statistical analysis software. According to the repeated attempt from low order to high order, until the data differential sequence is basically evenly distributed on the lower and lower sides of the 0 scale, the sequence stabilizes, finally determines the order of the time series, and determines the $d$ value.

According to the SPSS output, the self-correlation function graph and the partial correlation function graph tail ingg, whether there is a clear convergence trend, can establish ANARIMA ( $p, d$, q) model for the smooth differential sequence. Taking the situation of China's health manpower in the next 6 years as an example, it is assumed that the ARIMA model is used to predict medical graduates from Chinese medical colleges and universities while other social factors remain the same. Based on the optimal principle, the parameters of the medical graduate prediction model ARIMA ( $p=1, d=2, q=0$ ) were selected. The square difper of the predicted model is 0.987.9, 
indicating that the model is highly fitted. RMSE s 46366.04, MAPE s 7.744\%, MAE s 31717.38, MAXAE s 141820.73, normalized BIC s 21.865; Q medical graduates s.20.726, P medical graduates 0.23. 0.05; The residual white noise test further suggests that the prediction model is well fit. See the figure below. The above 8 prediction models show that $p$ is 0.05 , and the hints are well fit.

The predicting parameters of the ARIMA model for medical students and various health personnel are detailed in Table 1.

Table 1. ARIMA model prediction parameters for medical students and various health personnel

\begin{tabular}{|c|c|c|c|c|c|c|c|}
\hline ategory & ARIMA & R2 & RMSE & MAPE N & MAE & MAXAE & $\mathrm{P}$ \\
\hline $\begin{array}{l}\text { al } \\
\text { ates }\end{array}$ & ) & 0 & 04 & $7.74 \%$ & 38 & 0.7321 & 20.726 \\
\hline $\begin{array}{l}\text { rst year } \\
\text { medical } \\
\text { Imission }\end{array}$ & & & & & & & \\
\hline 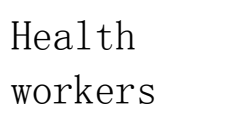 & $(0,2$ & 0.993 & 1394 & $1.13 \%$ & $84^{\prime}$ & 2723 & 12 \\
\hline cians & $(0$, & 0 & & $1.22 \%$ & 61 & 376 & 20. \\
\hline cians & $(0,2,1)$ & 0 . & 99502.26 & $2.51 \%$ & 530 & .123 .266 & 14 \\
\hline tered & $(0,2$, & 0.999 & 30994.27 & $1.27 \%$ & 20628. 12 & 86410.220 .934 & 25.004 \\
\hline acist & $(0,2$, & 0.826 & 15812.33 & $2.43 \%$ & 8729.72 & 45936.1119 .588 & 17.7230 .474 \\
\hline $\begin{array}{l}\text { aspection } \\
\text { echnician }\end{array}$ & $(1,2,0)$ & 0.967 & 7241.76 & $1.94 \%$ & 4607.15 & 7276.7618 .151 & 24.060 .118 \\
\hline
\end{tabular}

2.4Forecast trend of demand for all types of health personnel in China 2018-2024

By 2024, the demand for health personnel, health technicians, practicing (assistant) physicians, registered nurses, pharmacists and inspection technicians in China will reach 17.4563 million, 14.1829 million, 536.03 million, 666.08 million, 614.6 million and 520.3 million, respectively. This was $41.01 \%, 48.21 \%, 48.57 \%, 61.42 \%, 31.11 \%$ and $54.61 \%$, respectively, respectively, at the end of 2017. Among them, the largest increase in registered nurses.

The future demand forecast of various types of health personnel in China is detailed in Table 2. The future forecast of the demand of health workers per thousand population in China is detailed in Table 3.The forecast trend of the number of health personnel, health technicians, practicing (assistant) physicians, registered nurses, inspection technicians and pharmacists in China in the coming years is detailed as figures 1-6.

Table 2. Forecast of demand for all types of health workers in China (2018-2024)

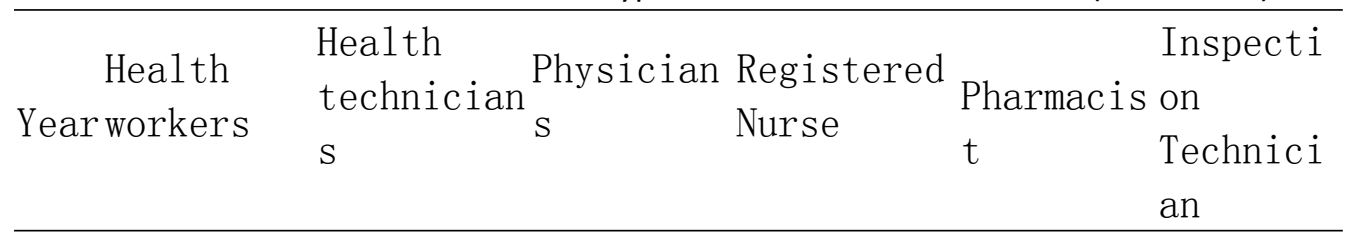




\begin{tabular}{rrrrrrr}
2018 & 12379265 & 9569624 & 3607920 & 4126390 & 468782 & 336537 \\
2019 & 13066605 & 10200837 & 3845540 & 4475425 & 486814 & 368304 \\
2020 & 13813770 & 10884118 & 4103770 & 4852275 & 507190 & 387681 \\
2021 & 14623540 & 11621718 & 4383487 & 5258091 & 530034 & 421375 \\
2022 & 15498695 & 12415888 & 4685568 & 5694025 & 555472 & 448518 \\
2023 & 16442014 & 13268879 & 5010890 & 6161227 & 583629 & 485817 \\
2024 & 17456277 & 14182941 & 5360329 & 6660848 & 614632 & 520304 \\
\hline
\end{tabular}

Table 3. Forecast swes of all types of health personnel per 1,000 population in China (2018-2024)

\begin{tabular}{|c|c|c|c|c|c|}
\hline Year & $\begin{array}{l}\text { Health } \\
\text { workers }\end{array}$ & $\begin{array}{ll}\text { Health } & \\
\text { technicia } & \text { Physicia } \\
\text { ns } & \text { ns }\end{array}$ & $\begin{array}{l}\text { Registered } \\
\text { Nurse }\end{array}$ & $\begin{array}{l}\text { Pharma } \\
\text { cist }\end{array}$ & $\begin{array}{l}\text { Inspectio } \\
\mathrm{n} \\
\text { Technicia }\end{array}$ \\
\hline
\end{tabular}

\begin{tabular}{rrrrrrr}
\hline 2018 & 8.85 & 6.84 & 2.58 & 2.95 & 0.34 & 0.24 \\
2019 & 9.28 & 7.25 & 2.73 & 3.18 & 0.35 & 0.26 \\
2020 & 9.73 & 7.67 & 2.89 & 3.42 & 0.36 & 0.27 \\
2021 & 10.21 & 8.11 & 3.06 & 3.67 & 0.37 & 0.29 \\
2022 & 10.70 & 8.57 & 3.24 & 3.93 & 0.38 & 0.31 \\
2023 & 11.21 & 9.04 & 3.42 & 4.20 & 0.40 & 0.33 \\
2024 & 11.71 & 9.52 & 3.60 & 4.47 & 0.41 & 0.35 \\
\hline
\end{tabular}

Figure 1 Observed and fitted number(with $95 \% \mathrm{LCL}$ and $\mathrm{UCL}$ ) of health workers in the public healthcare sector of China(1990 to 2017)and the forecast by the year 2024.

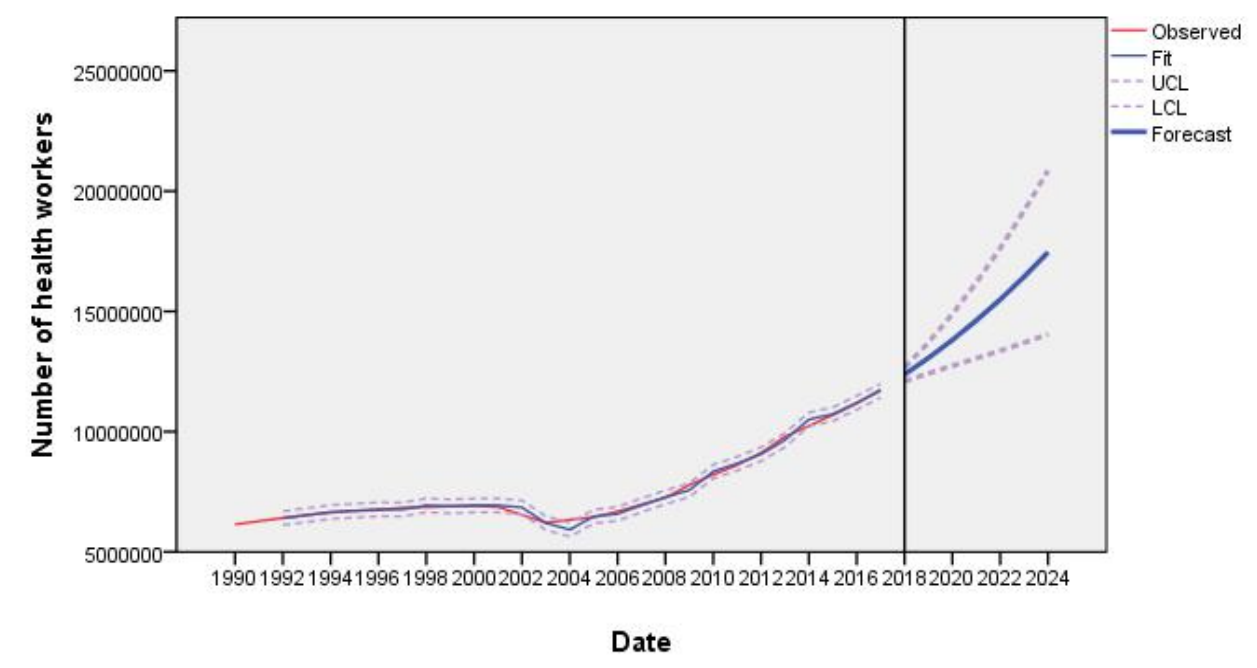

Figure 2 Observed and fitted number(with 95\% LCL and UCL)of health technicians in the public healthcare sector of China(1990 to 2017)and the forecast by the year 2024. 


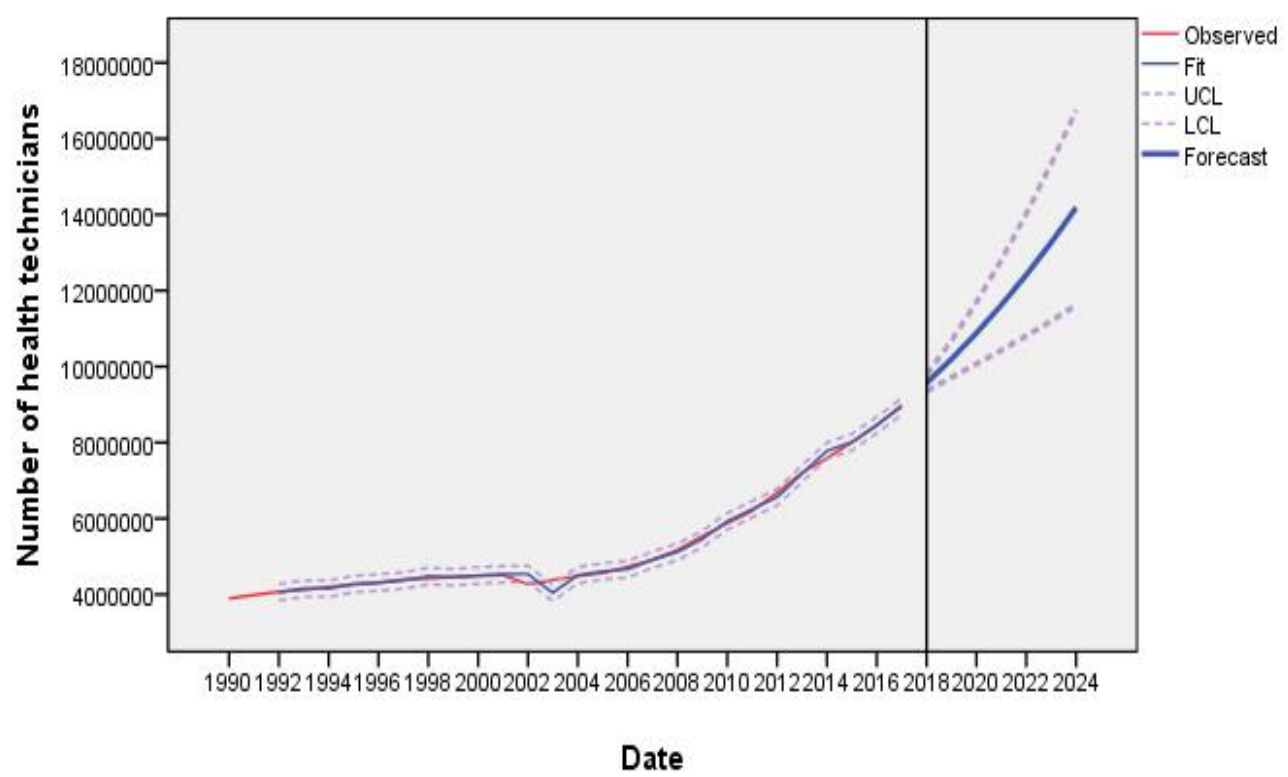

Figure 3 Observed and fitted number(with 95\% LCL and UCL)of physicians in the public healthcare sector of China(1990 to 2017)and the forecast by the year 2024.

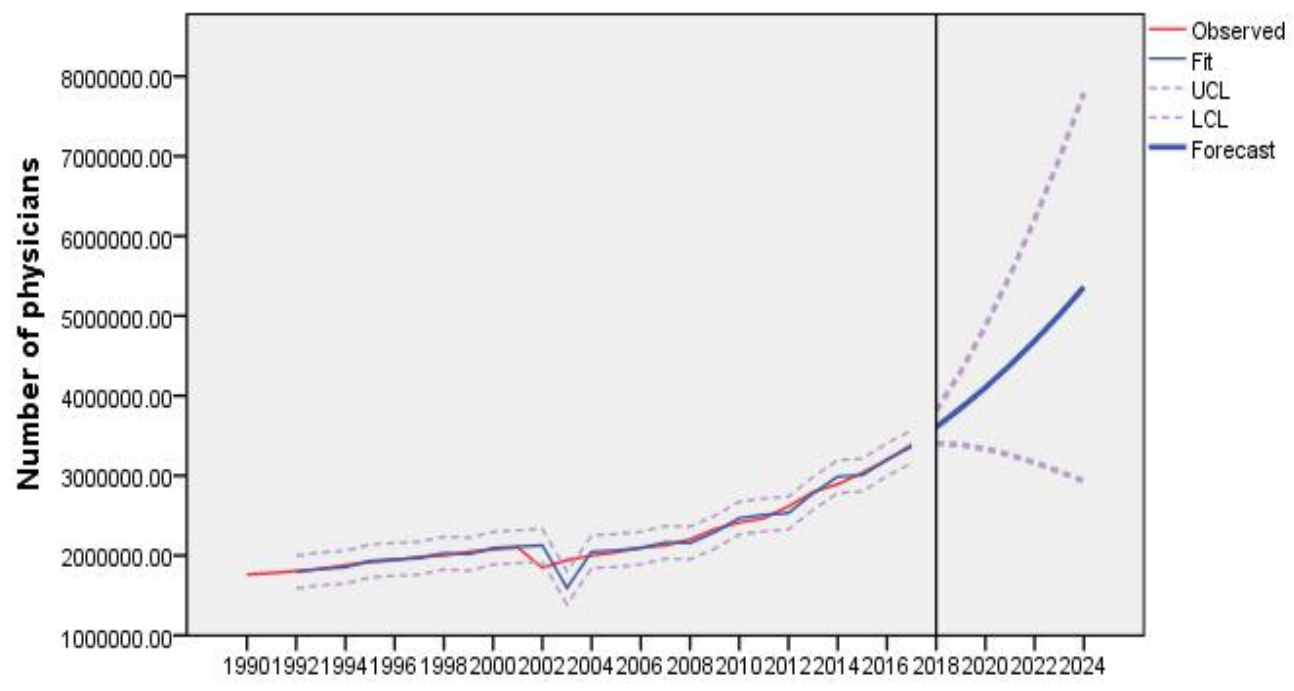

Date

Figure 4 Observed and fitted number(with 95\% LCL and UCL)of nurses in the public 


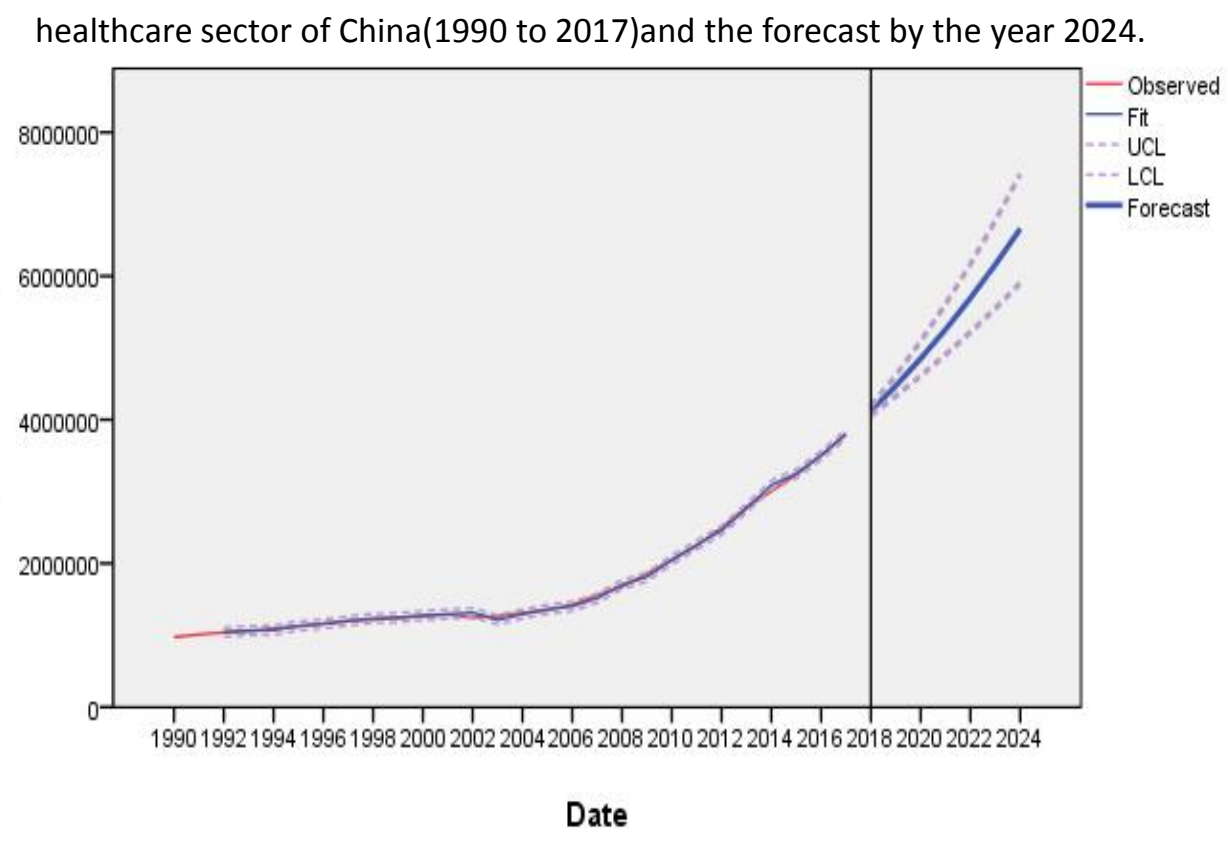

Figure 5 Observed and fitted number(with 95\% LCL and UCL) of inspection technicians in the public healthcare sector of China(1990 to 2017)and the forecast by the year 2024.

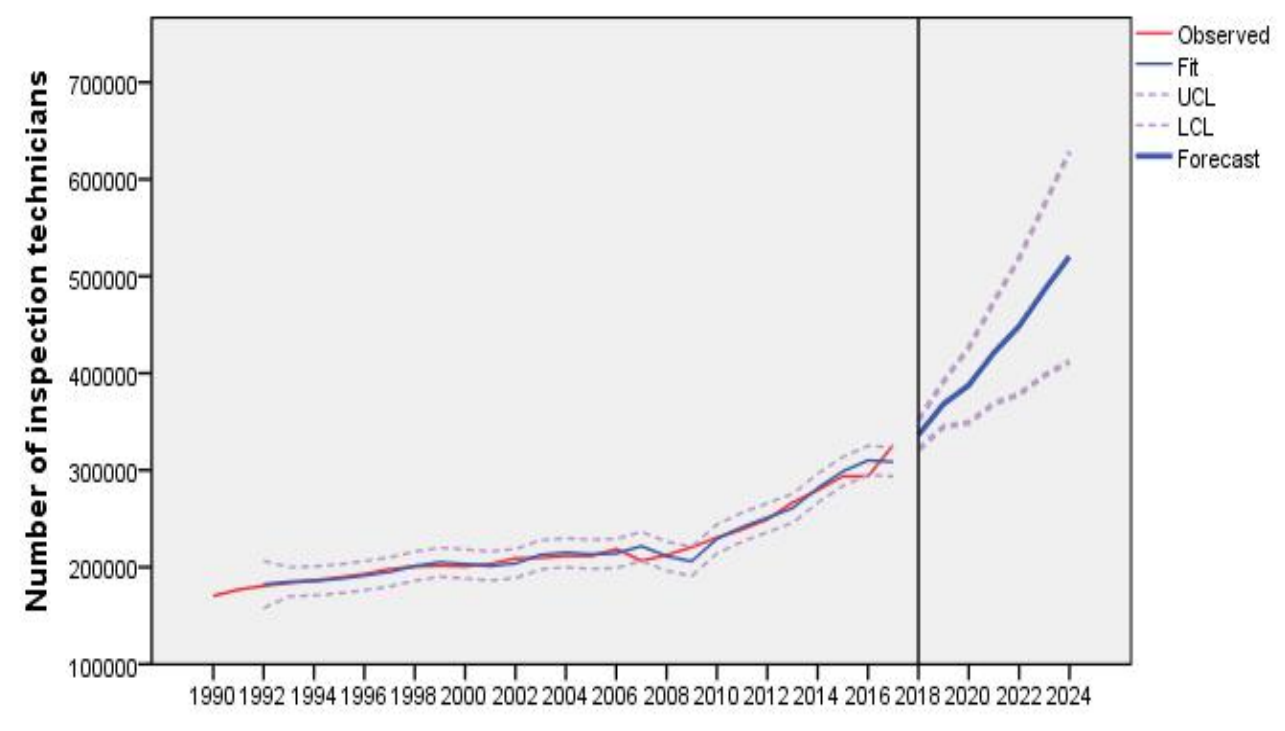

Date 
Figure 6 Observed and fitted number(with 95\% LCL and UCL)of pharmacists in the public healthcare sector of China(1990 to 2017)and the forecast by the year 2024.

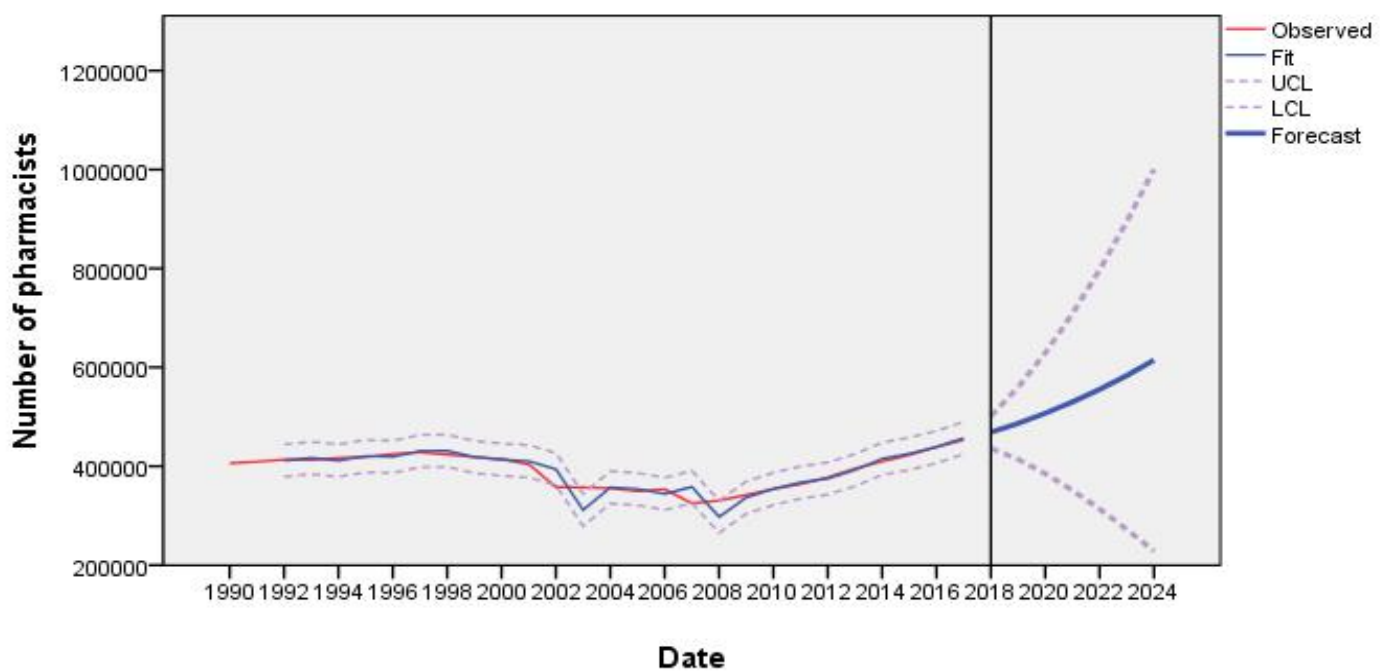

\subsection{Trends in Admissions and Medical Graduates in Chinese Medical Colleges}

Judging from the trend of enrollment, the number of students enrolled in Chinese medical colleges and universities increased from 140,033 in 1990 to 1229998 in 2017, and the number of students enrolled in Chinese secondary and higher education colleges increased by 778.36 percent in 28 years, at an average annual rate of 8.38 percent. Judging from the trend of medical higher education graduates, the number of Chinese medical students graduated increased from 137,056 in 1990 to 1167775 in 2017, an increase of 752.04 percent over 28 years, with an average annual growth rate of 8.26 percent, slightly less than the annual enrollment growth rate of 8.38 percent. China's medical graduates in the next few years, the first year of medical enrollment forecast trends detailed as shown in figure 7-8.

Figure 7 Observed and fitted number(with $95 \% \mathrm{LCL}$ and $\mathrm{UCL}$ ) of graduated medical students in the public healthcare sector of China(1990 to 2017)and the forecast by the year 2024.

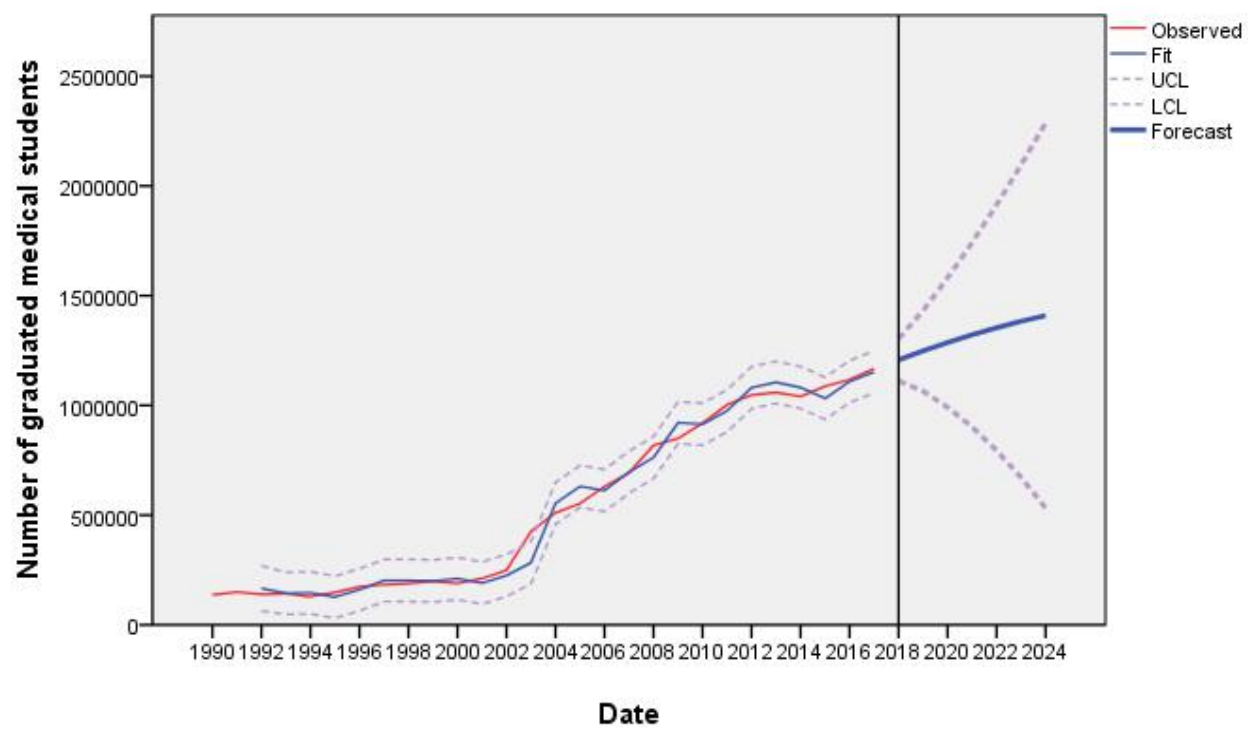

Figure 8 Observed and fitted number(with 95\% LCL and UCL) of first year medical students in the public healthcare sector of China(1990 to 2017)and the forecast by the year 2024. 


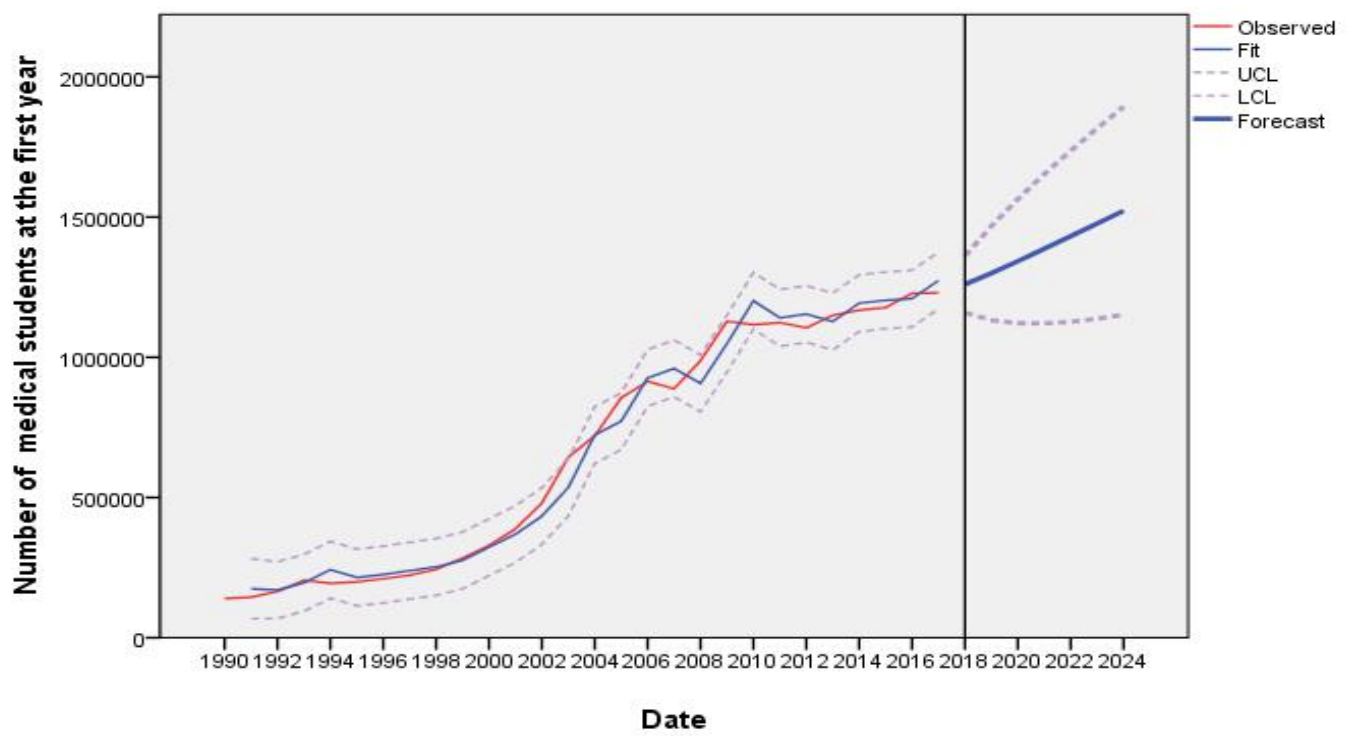

2.5 Forecast of supply and demand of China's health workforce

In addition to the productivity analysis of the full-time workload of the stock of manpower, the forecast of health manpower supply mainly uses the inflow and outflow analysis of existing health personnel, and combines the forecast of future medical graduates to complete the forecast of the total supply. The forecast assumes a steady trend in the level of productivity in the health education sector. The supply of health human resources $S$ - the stock value of the existing health manpower, the medical graduates trained by local high schools and other medical colleges - staff loss. According to documentation estimates, the targeting of health staff losses is about 5 per cent of the health workforce per year. The supply of overall health personnel in China's target year can be calculated. Based on the 2017 stock of 11.749 million health workers in China, the net inflow of medical students (about equal to the number of graduates) for 2024, and the annual depletion of the health workforce by about $5 \%$, can be calculated to be 15.9704 million people by 2024. Based on the demand and supply forecast of the number of health workers in China, the gap in the number of health workers in the future is analyzed. Details of supply and demand are shown in Table 4.

Table 4. Forecast of supply and demand for China's health workforce

(2018-2024)

\begin{tabular}{|c|c|c|c|c|c|c|}
\hline Year & $\begin{array}{l}\text { Health } F \\
\text { supply }\end{array}$ & $\begin{array}{l}\text { ersonnel } \\
\text { (S ) }\end{array}$ & $\begin{array}{l}\text { Health } p \\
\text { demand }\end{array}$ & $\begin{array}{l}\text { rsonnel } \\
\text { (D) }\end{array}$ & $\begin{array}{l}\text { Supply and } \\
\text { demand gap } \\
\text { (S-D) }\end{array}$ & $\begin{array}{l}\text { Gap growth } \\
\text { rate }(\%)\end{array}$ \\
\hline 2018 & & 12314027 & & 12379265 & -65238 & \\
\hline 2019 & & 12906363 & & 13066605 & -160242 & $145.62 \%$ \\
\hline 2020 & & 13509991 & & 13813770 & -303779 & $89.58 \%$ \\
\hline 2021 & & 14121028 & & 14623540 & -502512 & $65.42 \%$ \\
\hline 2022 & & 14736889 & & 15498695 & -761806 & $51.60 \%$ \\
\hline 2023 & & 15354381 & & 16442014 & -1087633 & $42.77 \%$ \\
\hline 2024 & & 15970404 & & 17456277 & -1485873 & $36.62 \%$ \\
\hline
\end{tabular}




\section{Discussion}

3. Discussion

3.1 China's total health manpower is relatively adequate, the proportion of medical care is unreasonable, medical personnel are inadequately equipped, the distribution of health human resources imbalance is China's health human resources allocation is facing a great challenge.

According to a report by the authoritative American Medical Institute's Medical Supply Council, most studies since the 1980s have concluded that doctors have oversupplied the country as a whole. However, despite the surplus of doctors, the regional imbalance in the distribution of doctors persists. The U.S. Medical Graduate Education Commission sees this as a central problem for the U.S. health service, namely, the shortage of excess. In terms of growth rate, the growth rate of China's human resources for health is higher than that of the total number of professional and technical personnel and the growth rate of the population, but it is much slower than the rate of economic development. Chinese a large number of mouths, the total amount of human resources for health is rich, but there are still some problems, first of all, due to the large base of Chinese mouth, the average population of all types of health technicians are mostly below the world average. Secondly, the imbalance in the distribution of human resources in health is also a more serious problem facing China's human resources for health, from the regional aspects of the eastern, central and western regions and the number of health personnel per thousand population in urban and rural areas, the number of health personnel per thousand population in eastern China is significantly higher than in the central and western regions. The number of health workers per thousand population in the central region is generally higher than in the west. By city and county, the number of health workers per thousand population in urban areas is higher than in rural areas, basically between 2-4 times the number of health workers per thousand population in rural areas. According to the statistics at the end of 2017, in the professional distribution of health and technical personnel in China, the proportion of medical personnel accounted for $41.39 \%$ and $32.87 \%$ respectively, respectively, the proportion of pharmaceutical, inspection and other specialties was $6.57 \%, 6.07 \%$ and $13.09 \%$ respectively. Until 2014 , the health care ratio had been inverted, with a 1:1.04 ratio since 2014, which was able to improve. According to the planning objectives of China's Medium- and Long-Term Talent Development Plan for Medical and Health (2011-2020) and the Outline of the National Health Service System (2015-2020), 2015, The number of practicing (assistant) physicians and registered nurses per 1,000 population was 2.21 and 2.36, exceeding the planned target of 1.88 and 2.07. The international health care standard published by the International Health Organization is 1:2, although China's health care ratio rose from 1:0.55 in 1990 to 1:1.12 at the end of 2017, but still a long way from international standards, The shortage of nursing staff in China is still very serious, the construction of nursing personnel needs to be further strengthened. In order to improve the proportion of medical care, the shortage of nursing staff, the urgent task is to change the long-standing "heavy care and prevention" of the traditional concept, adjust the structure of medical education, increase the medical colleges and universities to nursing and related professional health personnel training efforts; Improve the working conditions of nurses, appropriately improve the salary treatment of nursing staff, improve the stability of nursing personnel, and avoid the loss of nursing talent.

3.2 ARIMA model predicts that China's health care population will continue to increase, the 
health care ratio has improved, and the enrollment of higher medical education has become the mainstream of Medical Education in China, but the proportion of high-level medical graduates is low.

According to the model forecast, by 2024, China's various types of health personnel have different degrees of sustained growth. In 2017-2024, the number of health personnel, health technicians, practicing (assistant) physicians, registered nurses, inspection technicians and pharmacists will increase by 18.15 million, 10.0million, 157.8 million and 0.31 million, respectively. By 2020, the health care ratio will be 1:1.18, still a long way from the 2020 health care ratio of 1:1.25 set out in China's Medical and Health Medium- and Long-Term Talent Development Plan (2011-2020) and the National Health Service System Planning Framework (2015-2020). According to the forecast, the number of registered nurses per 1,000 population and the population of 1,000 will be 2.89 and 3.42 respectively by 2020, well above the planning target of 2.5 and 3.14. By 2024, the number of health workers per 1,000 population in China will reach 11.71 , the number of health technicians per 1,000 population will reach 9.52 , the number of medical practitioners and registered nurses per 1,000 population will reach 3.60 and 4.47 respectively, and the overall health care ratio will reach 1:1.24, still falling short of the international standard of 1:2.And the forecast shows that the increase in the number of pharmacists and test technicians is still limited in the short term.

According to a survey of Barzansky Barbara[34] medical schools accredited by the U.S. Medical Education Liaison Council (LCME), the total enrollment of 141 medical schools in the 2014-2015 academic year was 80,755. The total enrollment of 151 medical schools in the 2018-2019 academic year was 86,044, from an average of 573 in the 2014-2015 academic year to 570 in the 2018-2019 academic year, a trend that is in contrast to the rapidly increasing enrollment of chinese secondary schools and students. In the 28 years from 1990 to 2017, the number of students enrolled in higher medicine reached 593,030 each year until 2011, surpassing for the first time 530,467 students in secondary medicine, and the number of higher medical students increased at an average annual rate of $5.3 \%$, while the average rate of secondary medical students decreased at a rate of 3.787 percent. Among them, the number of medical master's students in 1997 increased from 6,452 to 86,539 in 2017 at an average annual rate of $13.86 \%$. It is suggested that the enrollment scale of higher medical education has increased significantly, which has become the mainstream of medical education in China, among which the enrollment scale of medical master's degree has increased rapidly, and the enrollment level of medical education in China is being greatly improved. Although the number of m.S. graduates in 28 years has increased year by year at a rate of 10.18 percent, the number of medical graduates with master's degree in 2017 was 66,869, accounting for only 5.73 percent of the total number of graduates, which on the other hand suggests that the proportion of high-level medical graduates is low.

3.3 China's health workforce is forecast to grow rapidly in the next few years, but it is still not as fast as demand growth, and the quantitative gap is still gradually widening in the short term, and the pressure on medical and health institutions and medical education institutions is greater.

From China's overall future health manpower demand and supply comparison, although the number of medical graduates in the rapid increase, but still can not keep up with the health 
manpower demand increase, 2018-2024 the overall gap between the supply and demand of health manpower is still gradually widening. By the end of 2024, the number of health workers in China will reach about 1.4859 million. The whole cause may be related to the health manpower training cycle is long, high cost and other factors, both in quantity and quality have lag. However, the growth rate of the supply and demand gap has decreased from $145.62 \%$ in 2019 to $36.62 \%$ in 2024 , and it is clear that the gap is gradually decreasing. A Chinese scholar has found that the number of medical higher education graduates in a province in the central region is greater than the annual increase of health personnel, the supply is greater than the demand, the total number of graduates of medical colleges and universities is excessive, and the analysis exists the problem of employment difficulties for some graduate medical students. Of course, this focus on the supply and demand of a region's health manpower is limited, because the central region of Hubei Province, China's economy is more developed, and as a national education province, Hubei Province medical education in the country has a wide range of social influence, at least 13 medical-related institutions, the opening of professional covering basic medicine, preventive medicine, Clinical medicine and medical technology, oral medicine, Chinese medicine, forensics, nursing, pharmacy and other eight majors, for Hubei Province and the whole country to train a large number of health personnel, to protect the health of residents provide a strong support. However, from the perspective of the supply and demand of the national overall health human resources, health personnel are still in a state of in short supply. It is suggested that China's education departments and the administrative departments of health and family planning should attach great importance to the above situation, and the market demand for medical education and health manpower should be effectively connected, and communication between the education department and the health administrative department should be strengthened to improve the training efficiency of medical students.

In the face of the difficult situation of the health manpower gap in this study, China should actively explore scientific health manpower demand forecasting models or methods, health departments at all levels must pay more attention to scientific health manpower forecasting and planning, and make good use of the guiding role of forecasting and planning, while dynamic monitoring and evaluation of the planning process, timely adjustment. To solve the gap in the quantity, structure and quality of health manpower, we first need to expand the scale of medical education and improve the quality of medical education. According to the annual demand growth of the health manpower, the reasonable goal of the structure of health technicians in various professional categories is to determine the enrollment scale of medical students in various medical colleges. To strengthen communication and communication between the administrative departments of health and family planning and the education departments, the administrative departments of health and family planning shall timely transmit the forecast results of the demand for health manpower to the education sector, so that the education sector can adjust the scale and direction of medical education according to the professional categories and quantities of health personnel required, based on the projections of the demand for health manpower,To avoid the blindness of medical enrollment, medical students to train too fast, and so on, to train health personnel to meet different needs, to promote the balance of supply and demand of health manpower. 
1. Chant A D.A confusion of roles:manpower in the National Health Service[J].J.R.Soc.Med,1998,91:63-65.

2. O'Brien E,Gavel P,Curnow J,et al.Nursing workforce planning in Australia:A guide to the process and methods used by the Australian Health Workforce advisory Committee[J]Australian Health Workforce Advisory Committee,2004.

3. Birch S.Health human resource planning for new millennium:inputs in the production of health,illness, and recovery in populations[J].The Canadian Journal of Nursing Research,2002,33(4):109-114.

4. Grossman M.On the Concept of health capital and the demand for Health[J].Journal of political Economy,1972,80(Volume 80,Number 2):223-255.

5. Fuchs V R.The Future of Health Economics[M]//Who Shall Live?:Health,Economics and Social Choice(2ndExpanded Edition).:227-244.

6. Henderson J W,Williams B.Health Economics Worldwide:Developments in Health Economics and Public Policy,by Peter Zweifel;H.E.Frech[J]Journal of Risk and Insurance,1994,61(1)151.

7. Newhouse J P,Culyer A J,Frank R,et al.Journal of Health Economics[M]//Journal of health economics. North-Holland,1982:1073-1084.

8. Mcguire A,Henderson J,Mooney G.The economics of health care:an introductory text.[M]//The economics of health care:an introductory text.Routledge,1988:849-853.

9. Nordhaus W.Productivity Growth and Employment[J]Health Economics.

10. Mooney G.Vertical equity in health care resource allocation[J]Health Care Analysis,2000,8(3):203-215.

11. Neuhalser D.The really dffective health service delivery system[J]Health Care Manage Review,1976,1(1):25-32.

12. Mooney G.Resource allocation and aboriginal health[J].August New Zealand Journal of Public Health,1996,20(1):9.

13. McDermott R,Beaver C,Zhao Y.Outcomes-based resource allocation for indigenous health services:a model for northern Australia[J]. Health Policy,1997,39(1):69-78.

14. Smith CS,Hailey D,Drummond M.The role of economic appraisal in health technology assessment:The Australian case[J].Social Science and Medicine,1994,38(12):1653-1662.

15. Salkeld G,Davery P,Arnolda G.A critical review of health-related economic evaluations in Australia:implications for health policy[J].Health Policy,1995,31(2):111-125.

16. Paul.F Hogan. Physical Medicine and Rehabilitation Workforce Study :The Supply and Demand for Physiatrist[J].Arch Phys Rehab,2000(177):95-99.

17. Oiga Jonasson. Calculating the Workforce in General Surgery[J].JAMA, 2006,274(9):731-734.

18. Conant G, Kleiner $\mathrm{BH}$. Human resource management in the health care industry[J]. Health Manpower Manage,2007,24(2-3):114-118.

19. Finn Diderchsen, Eva Varde, Margaret Whitehead. Resource allocation to health authorities: the quest for equitable formula in Britain and Sweden[J]. BMJ,2004,315:875-878.

20. Gorman D.Developing health care workforces for uncertain futures[J].Acad Med,2015,90(4):400-3.

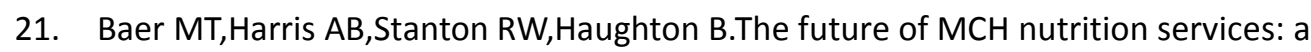


commentary on the importance of supporting leadership training to strengthen the nutrition workforce[J].Matern Child Health J,2015,19(2):229-35.

22. Cunningham R.Challenges of Forecasting Physician Workforce Needs Amid Delivery System Transformation[J].Issue Brief Natl Health Policy Forum,2015, 29(855):1-14.

23. Ansah JP,De Korne D,Bayer S,Pan C,Jayabaskar T,Matchar DB, Lew N,Phua A, Koh V,Lamoureux E,Quek D.Future requirements for and supply of ophthalmologists for an aging population in Singapore[J].Hum Resour Health. 2015,(13):86.

24. Nigenda G,Muños JA.Projections of specialist physicians in Mexico: a key element in planning human resources for health. [J].Hum Resour Health. 2015,(13):79.

25. DSa MM,Nakagawa RS,Hill DS,et al. Exponential smoothing method for forecast drug expenditures[J]. American journal of hospital pharmacy,2009,51(20): 2581-2588.

26. Algranti E,Saito CA,Carneiro AP, Moreira B,Mendonça EM,Bussacos MA.The next mesothelioma wave: mortality trends and forecast to 2030 in Brazil[J].Cancer Epidemiol. 2015,39(5):687-92.

27. Steinhardt LC,Onikpo F,Kouamé J,Piercefield E,Lama M, Deming MS, Rowe AK.Predictors of health worker performance after Integrated Management of Childhood Illness training in Benin: a cohort study[J].BMC Health Serv Res. 2015,(15):276.

28. Wang S,Petzold M,Cao J,Zhang Y,Wang W.Direct medical costs of hospitalizations for cardiovascular diseases in Shanghai, China: trends and projections[J].Medicine (Baltimore),2015,94(20): 837.

29. Primack WA, Meyers KE, Kirkwood SJ, Ruch-Ross HS, Radabaugh CL, Greenbaum LA.The US pediatric nephrology workforce: a report commissioned by the American Academy of Pediatrics[J].Am J Kidney Dis,2015,66(1):33-9.

30. Kalman RE.A new approach to linear filtering and predietion problems[J].Journal of Basic Engineering,1960,(82):35-45.

31. Kalman RE,Bucy RE.New results in linear filtering and prediction theory[J].Journal of Basic Engineering,1961,(83):95-108.

32. Hossain MZ,Samad QA,Ali MZ.ARIMA model and forecasting with three types of pulse prices in Bangladesh:a case study[J].International Journal of Social Economics,2006,33(4):344-353.

33. Contreras J,Espinola R,Nogales FJ,et al.ARIMA models to predict next-day electricity price[J].Power Systems, IEEE Transactions,2003,18(3):1014-1020.

34. Barzansky Barbara,Etzel Sylvia I. Medical Schools in the United States, 2018-2019.[J]. JAMA,2019,322(10).

LIU Qin is Ph.D.of Social Medicine and Public Health Management

BI Huai-mei is Dean of the School of Nursing, Professor, Professional for Nursing Management

$\mathrm{BI}$ Li-xiong is the vice president of the School of Nursing, an associate professor, specializing in Chinese medicine.

ZHANG Shuo-wei is a nursing college teacher, master's degree, majoring in nursing

FU Ying-ping is a nursing college teacher, master's degree, majoring in nursing

(Corresponding Author)CHANG Ren-jie is the attending physician of the Department of Gastroenterology, Third People's Hospital of Yunnan Province, Ph.D., specializing in digestive endoscopy. 
ORCID iD

LIU QIN https://orcid.org/0000-0002-1929-2686

Funding

The author(s) received no financial support for the research, author ship, and/or publication of this article.

Acknowledgements

Not applicable.

Availability of data and materials

The datasets used and/or analysed during the current study are available from the corresponding author on reasonable request.

Authors' contributions

LIU Qin conceived the study and were responsible for its implementation and completion. CHANG Ren-jie and BI Huai-mei carried out the data analysis, $\mathrm{BI}$ Li-xiong produced the figures and tables. LIU Qin and CHANG Ren-jie wrote the manuscript. All authors had final approval of the submitted and published versions.

Author details

${ }^{1}$ School of Nursing,Yunnan University of Chinese Medicine,Kunming, Yunnan,China,650500;

${ }^{2}$ Digestive medicine of third People's Hospital,,Kunming, Yunnan,China,650011.

Ethics approval and consent to participate

This study used anonymized datasets and thus did not require ethics approval.

Consent for publication

Not applicable.

Competing interests

The authors declare that they have no competing interests. 